\title{
CORRIGENDUM
}

\section{DNA barcoding of five common stored-product pest species of genus Cryptolestes (Coleoptera: Laemophloeidae) - CORRIGENDUM}

\author{
Y.J. Wang, Z.H. Li, S.F. Zhang, Z. Varadínová, F. Jiang, \\ Z. Kučerová, V. Stejskal, G. Opit, Y. Cao and F.J. Li
}

doi:10.1017/S0007485314000224, Published by Cambridge University Press, 11 April 2014.

The authors apologise for errors in Table 1 on page 3 of the original version of this article.

Table 1. Specimens of Cryptolestes used in the study.

\begin{tabular}{|c|c|c|c|c|}
\hline Species & Collection locality & Stage & $N(\mathrm{H} n)$ & Accession number \\
\hline$\overline{\text { C. ferrugineus }}$ & $\begin{array}{l}\text { Prague, Czech Republic } \\
\text { Kansas, USA } \\
\text { Shenzhen, Guangdong, China } \\
\text { Zhanjiang, Guangdong, China } \\
\text { Beihai, Guangxi, China } \\
\text { Jining, Shandong, China }\end{array}$ & $\begin{array}{l}\text { Adults } \\
\text { Adults } \\
\text { Adults } \\
\text { Adults } \\
\text { Adults } \\
\text { Larvae/adult }\end{array}$ & $\begin{array}{l}8 \text { (H1) } \\
5(\mathrm{H} 2) \\
2(\mathrm{H} 3) \\
2(\mathrm{H} 3) \\
3(\mathrm{H} 3, \mathrm{H} 4) \\
3(\mathrm{H} 3) / 12(\mathrm{H} 3, \mathrm{H} 4)\end{array}$ & $\begin{array}{l}\text { JQ708203 } \\
\text { KC977924 } \\
\text { JQ708204 } \\
\text { KC977925 } \\
\text { KC977926 and KC977927 } \\
\text { KC977928, KC977929 and KC977915 }\end{array}$ \\
\hline C. pusillus & $\begin{array}{l}\text { Prague, Czech Republic } \\
\text { Eastern Kansas, USA } \\
\text { Haikou, Hainan, China } \\
\text { Wuhan, Hubei, China }\end{array}$ & $\begin{array}{l}\text { Adults } \\
\text { Adults } \\
\text { Adults } \\
\text { Adults }\end{array}$ & $\begin{array}{l}5(\mathrm{H} 1) \\
3(\mathrm{H} 2) \\
6(\mathrm{H} 3, \mathrm{H} 4) \\
7(\mathrm{H} 3, \mathrm{H} 4)\end{array}$ & $\begin{array}{l}\text { JQ708205 } \\
\text { KC977930 } \\
\text { JQ708206 and KC977931 } \\
\text { KC436317 and KC436318 }\end{array}$ \\
\hline C. pusilloides & $\begin{array}{l}\text { Beijing, China } \\
\text { Luxi, Yunnan, China }\end{array}$ & $\begin{array}{l}\text { Adults } \\
\text { Larvae/adult }\end{array}$ & $\begin{array}{l}3(\mathrm{H} 1) \\
3(\mathrm{H} 2) / 6(\mathrm{H} 1, \mathrm{H} 2)\end{array}$ & $\begin{array}{l}\text { KC } 436315 \\
\text { KC436316, KC977932 and KC } 977916\end{array}$ \\
\hline C. turcicus & $\begin{array}{l}\text { Prague, Czech Republic } \\
\text { Shangqiu, Henan, China }\end{array}$ & $\begin{array}{l}\text { Adults } \\
\text { Adults }\end{array}$ & $\begin{array}{l}12(\mathrm{H} 1) \\
3(\mathrm{H} 2)\end{array}$ & $\begin{array}{l}\text { JQ708207 } \\
\text { KC977933 }\end{array}$ \\
\hline
\end{tabular}

$N$ : the number of individuals used in the study.

$\mathrm{H} n$ : the serial number of haplotype contained in each Cryptolestes population.

\section{Reference}

Wang, Y.J., Li, Z.H., Zhang, S.F., Varadínová, Z., Jiang, F., Kučerová, Z., Stejskal, V., Opit, G., Cao, Y. and Li, F.J. DNA barcoding of five common stored-product pest species of genus Cryptolestes (Coleoptera: Laemophloeidae). Bulletin of Entomological Research. Published by Cambridge University Press, 11 April 2014. doi:10.1017/S0007485314000224. 